\title{
MECHANICAL STUDY ON DORSAL STABILITY OF INTRAMEDULLARY OSTEOSYNTHESIS ASSOCIATED WITH EXTERNAL FIXATION (ULSON'S METHOD)
}

Trajano Sardenberg ${ }^{1}$, Sérgio Swain Muller ${ }^{1}$, Daniel Ricardo Medeiros ${ }^{2}$, Pablo Luiz Baptistão ${ }^{2}$

\begin{abstract}
Objective: To evaluate the Ulson intramedullary fixation method, with external fixation in which the level of the external locking of the Kirschner wires is varied, and without external fixation. Methods: Eighteen porcine tibias were used. Transverse osteotomy was performed in the region of the tuberosity, and two intramedullary Kirschner wires were inserted into each specimen, using three different assembly patterns: Group I: locking with external minifixator at a height of $3.0 \mathrm{~cm}$; Group II: locking at a height of $4.5 \mathrm{~cm}$;
\end{abstract}

\section{INTRODUCTION}

Unstable and reducible extra-articular distal radius fractures can be treated with percutaneous pinning and the use of antebrachial-palmar plaster ${ }^{(1,2)}$. The method proposed by Ulson combines intramedullary percutaneous pinning with two Kirschner wires, with external locking of these wires using an external minifixator $^{(3)}$. Severo et $a l^{(4)}$ proposed modifications to the folding of the Kirschner wires, characterized by greater height of the site at which the wires are locked by the external mini-fixator, with the aim of facilitating flexion and extension movements of the wrist in the third week after surgery, and double folding of the medial wire, to facilitate its removal. However, increasing the distance between the connection with the bone and the external fixation can result in loss of stability of the assembly ${ }^{(5)}$.

The objective of this study was to mechanically
Group III: without external locking. Mechanical shear tests were then conducted, to determine the maximum load, proportionality limit and coefficient of rigidity. Results: There were no significant differences in maximum load or proportionality limit between the groups. The coefficient of rigidity was higher in Group II. Conclusion: The locking height for the Kirschner wires in Ulson's method, within the limits evaluated, did not harm the stability of the fracture fixation system.

Keywords - Radius Fractures; External Fixators; Biomechanics

evaluate the Ulson intramedullary fixation method associated with external fixation ${ }^{(3)}$, varying the height of the external locking of the Kirschner wires.

\section{METHODS}

Eighteen porcine tibias were used, from animals with an average age of six months, obtained from a slaughterhouse and preserved in a domestic freezer at $-20^{\circ} \mathrm{C}$ for four to seven days. On the day of the mechanical tests, the anatomical pieces were defrosted at room temperature, the soft parts were removed, and transversal osteotomy was carried out in the region of the anterior tuberosity, with a manual saw.

The orifice for insertion of the Kirschner wires ( $2 \mathrm{~mm}$ in diameter) was started off with an electric drill and completed manually. The Kirschner wires were locked with an external mini-fixator under manually applied tension.

\footnotetext{
1 - Professor, Botucatu School of Medicine - UNESP - Botucatu, SP, Brazil.

2 - Physician; Former Resident in Orthopedics and Traumatology of the Botucatu School of Medicine - UNESP - Botucatu, SP, Brazil.

Study conducted at the Department of Surgery and Orthopedics of the Botucatu School of Medicine - UNESP.

Mailing address: Departamento de Cirurgia e Ortopedia da Faculdade de Medicina de Botucatu - UNESP, Distrito de Rubião Junior s/n - 18603-970 - Botucatu, SP. Email: tsarden@uol.com.br

Study received for publication: 5/31/2010, accepted for publication: 6/16/2011.
}

The authors declare that there was no conflict of interest in conducting this work 
The intramedullary positioning of the wires was controlled by means of radiographic image.

The test samples were divided into three groups, according to the type of assembly:

Group I - intramedullary fixation with two Kirschner wires of $2 \mathrm{~mm}$ in diameter and locking with an external mini-fixator at a height of $3.0 \mathrm{~cm}$ (Figure 1A);

Group II - intramedullary fixation with two Kirschner wires of $2 \mathrm{~mm}$ in diameter and locking with an external mini-fixator at a height of $4.5 \mathrm{~cm}$; in this group, the medial wire was folded, as proposed by Severo et $a l^{(4)}$ (Figure 1B); and

Group III - intramedullary fixation with two Kirschner wires of $2 \mathrm{~mm}$ in diameter, folded and cut, maintained without external locking (Figure 1C).

Figure 1 demonstrates the assemblies of groups I, II and III.

The test samples were submitted to the mechanical shear test in a mechanical universal testing machine, with load cell of $1000 \mathrm{~N}$ and load application speed of $30 \mathrm{~mm} / \mathrm{min}$. Figure 2 shows the system of fixation of the test sample and application of the load. After the test, the program of the machine coupled to a computer gave the values for mechanical maximum load $(\mathrm{N})$, limit of proportionality $(\mathrm{N})$, and coefficient of rigidity $(\mathrm{N} / \mathrm{mm})$.

The values were submitted to statistical analysis by means of analysis of variance for one-factor model, complemented by Tukey's test ${ }^{(6)}$ (comparisons between mean pairs of groups). All the conclusions were described at a level of 5\% significance $(\mathrm{p}<0.05)$.

\section{RESULTS}

Tables 1 and 2 and Figures 3, 4 and 5 show the results.

The statistical analysis indicated that in relation to maximum load and limit of proportionality, the behavior of experimental groups I, II and III was similar. On the other hand, for the coefficient of rigidity, the statistical analysis indicated that group II presented higher values than group I, which in turn, presented higher values than group III.

\section{DISCUSSION}

The study carried out presents limitations in relation to the mechanical test method and material used. The shear test only tested the dorsal stability of the distal fragment of the fracture, and did not evaluate deviations in laterality, rotation and shortening. Tests to evaluate stability in relation to shortening would certainly enrich the study, since for the treatment of the distal radius fractures, this parameter is important for analyzing the results obtained. However, shortening of the radius is associated principally with osteoporosis, which was absent in the present study as it used bones from young pigs without osteoporosis.

Porcine tibia, the material used for the fracture model, proved to be adequate, particularly for the measurements of the corticals of the metaphysiary and diaphysiary bones and the intramedullary canal. Therefore, the conclusions of the present study can only be considered in relation to stabilization of the extra-articular metaphysiary fracture in bone without osteoporosis, and in relation to dorsal deviation. Oliveira Filho et $a l^{(7)}$, Saeki et $a l^{(8)}$ and Pehlivan et $a l^{(9)}$ performed experimental studies with methodological

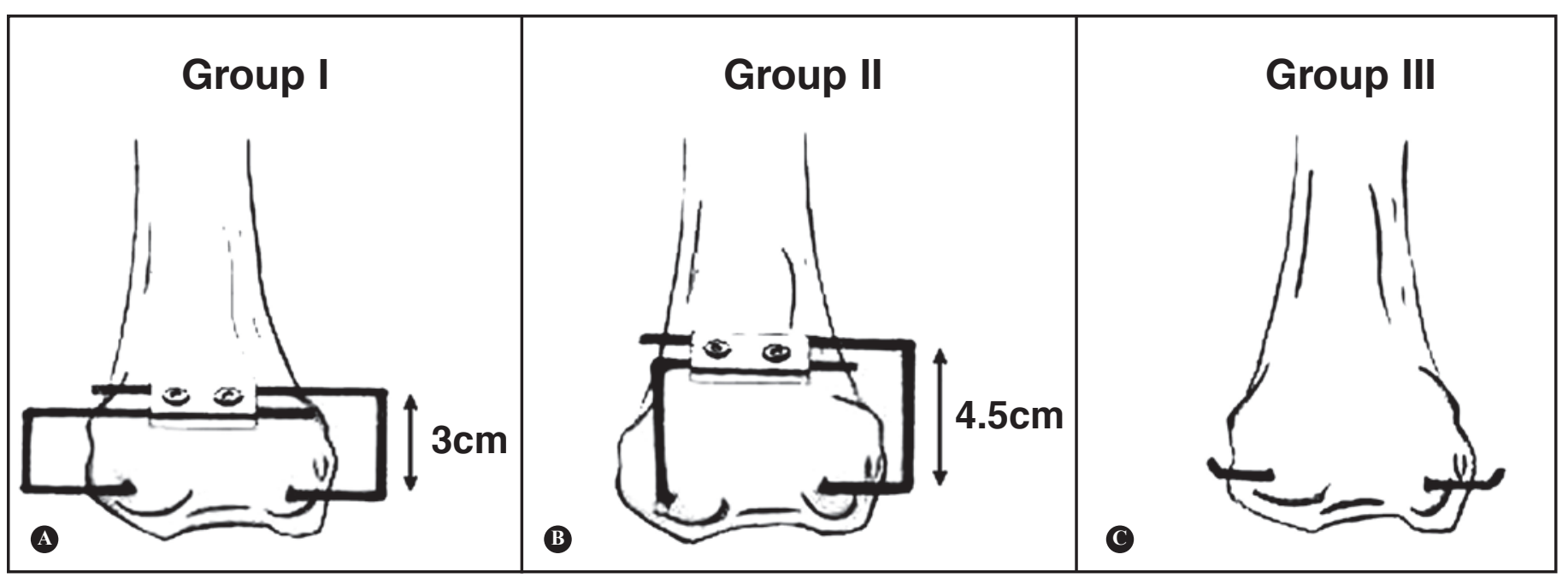

Figure 1 - Intramedullary fixation assemblies associated with external fixation of the test samples used in groups I, II and III. 

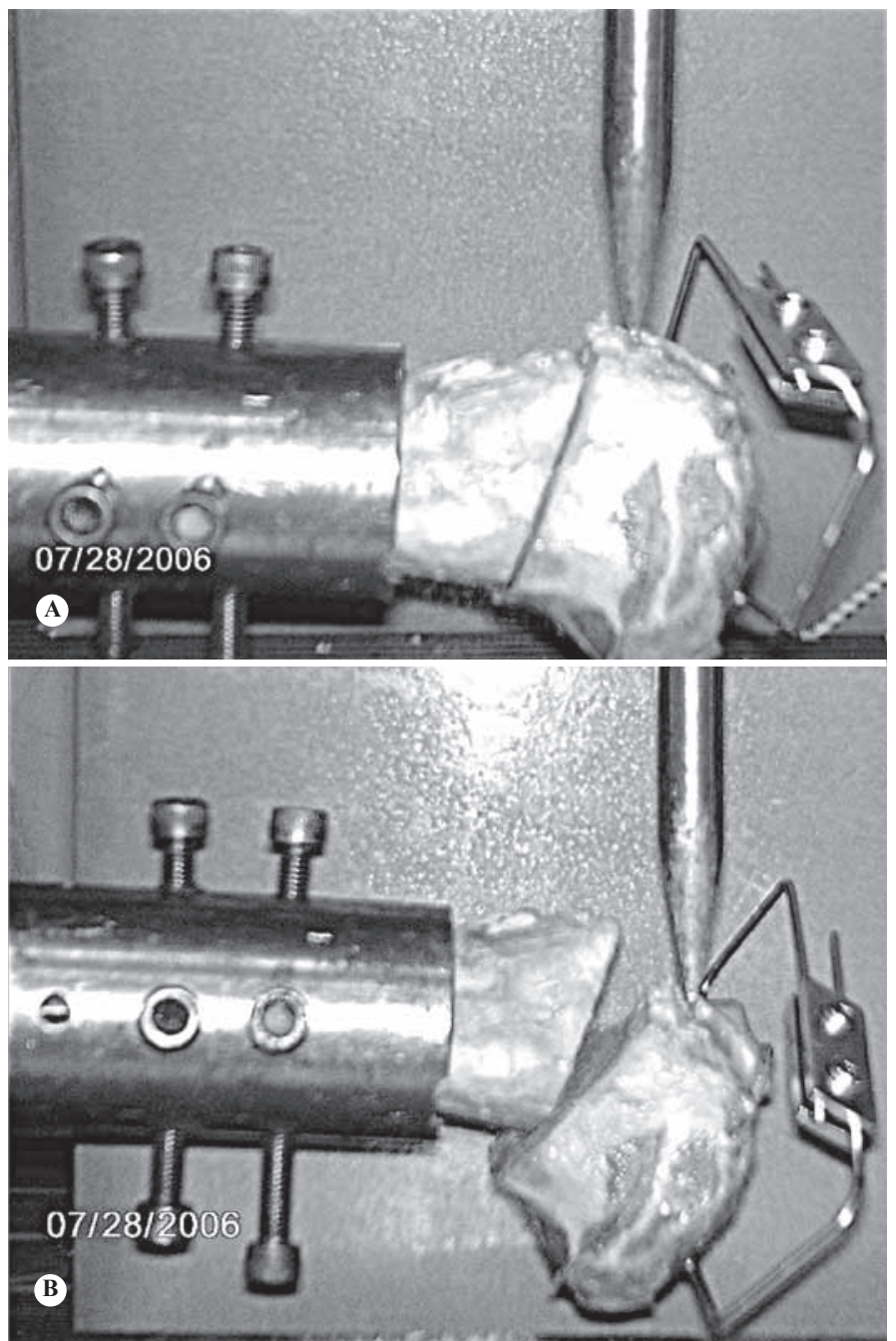

Figure 2 - A) Test sample fixed in the mechanical universal testing machine for the shear test; $B$ ) Test sample at the end of the mechanical test.

Table 1 - Mean and standard deviation of the variables by group.

\begin{tabular}{|c|c|c|c|c|}
\hline \multirow{2}{*}{ Variable } & \multicolumn{3}{|c|}{ Group } & \multirow{2}{*}{$\begin{array}{c}\text { Statistical } \\
\text { result } \\
\text { (p-value) }\end{array}$} \\
\hline & Group I & Group II & Group III & \\
\hline $\begin{array}{l}\text { Maximum load } \\
(\mathrm{N})\end{array}$ & $337 \pm 117 a$ & $396 \pm 142 a$ & $245 \pm 45 a$ & $\begin{array}{c}p>0.05 \\
(p=0.085)\end{array}$ \\
\hline $\begin{array}{l}\text { Limit of } \\
\text { proportionality } \\
(\mathrm{N})\end{array}$ & $285 \pm 64 a$ & $269 \pm 72 a$ & $207 \pm 27 a$ & $\begin{array}{c}p>0.05 \\
(p=0.105)\end{array}$ \\
\hline $\begin{array}{l}\text { Coefficient of } \\
\text { rigidity }(\mathrm{N} / \mathrm{mm})\end{array}$ & $38 \pm 16 a b$ & $47 \pm 17 a$ & $26 \pm 6 b$ & $\begin{array}{c}p<0.05 \\
(p=0.031)\end{array}$ \\
\hline
\end{tabular}

Table 2 - Statistical analysis of the results.

\begin{tabular}{|c|c|}
\hline Variable & Analysis of the results \\
\hline Maximum load (N) & Group I $\cong$ group II $\cong$ group III \\
\hline Limit of proportionality $(\mathrm{N})$ & Group I $\cong$ group II $\cong$ group III \\
\hline Coefficient of rigidity $(\mathrm{N} / \mathrm{mm})$ & Group II > group I > group III \\
\hline
\end{tabular}

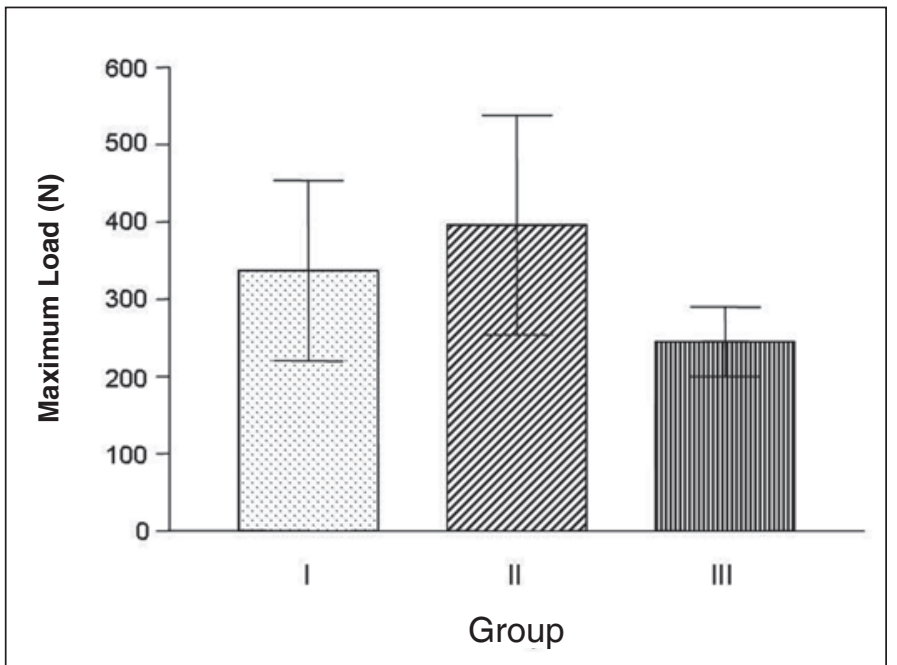

Figure 3 - Mean and standard deviation of the values obtained for maximum load $(\mathrm{N})$ in each experimental group.

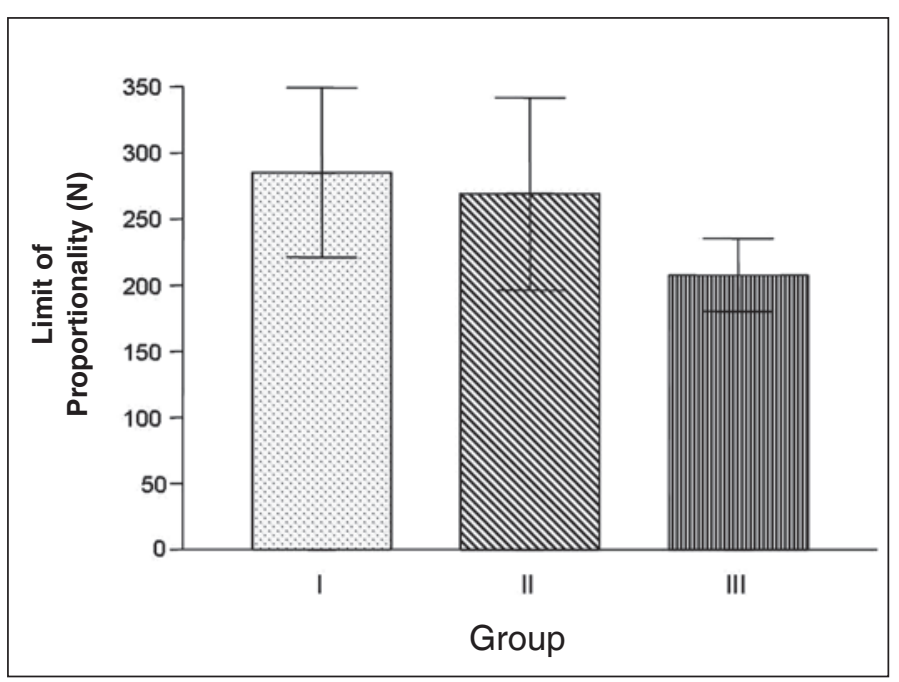

Figure 4 - Mean and standard deviation of the values obtained for the limit of proportionality $(\mathrm{N})$ in each experimental group.

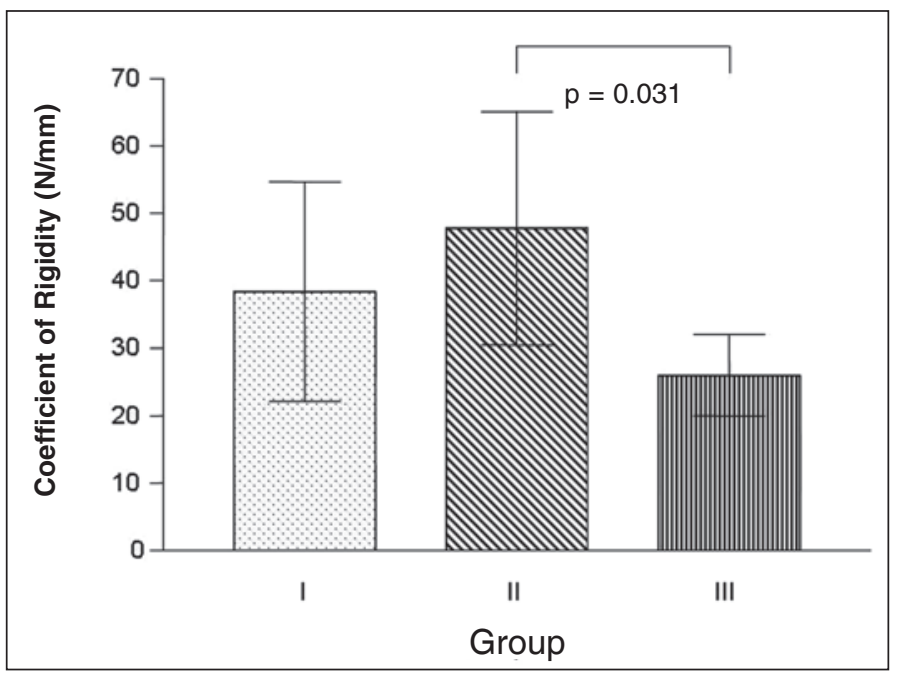

Figure 5 - Mean and standard deviation of the values obtained for the coefficient of rigidity $(\mathrm{N} / \mathrm{mm})$ in each experimental group. 
differences, in relation to the mechanical tests and the materials used, similar to the present study, which reveal the difficulties involved in performing the tests, and in comparing the results of biomechanical studies.

The central idea of this study was to evaluate whether changes to the folding of the Kirschner wires in the Ulson method, used in the treatment of distal radius fractures, proposed by Severo et $a l^{(4)}$, with the objective of facilitating the movement of the wrist and removal of the wire placed in the medial side of the radius, would be harmful to the stability of the fixation system.

The results obtained indicated that there were no statistical differences in the mechanical parameters for maximum load and limit of proportionality evaluated in groups I, II and III. However, in relation to the mechanical property coefficient of rigidity, the results indicate that group II, with higher locking of the Kirschner wires and simpler folding of the medial wire, presented higher values than group I, which in turn, presented higher values than group III, in which the Kirschner wires were not locked. These results demonstrated that increasing the height of the locking site, and altering the fold of the medial wire, did not totally alter the stability of the system. The results obtained contradict the concept that the greater the distance between the connection with the bone and the fixation, the lower the stability of the assembly of the external fixators, as explained by Dell'Oca ${ }^{(5)}$. These results indicate that within determined limits, it is possible to increase the height of the fixation site in the assembly without diminishing the stability of the system. Determining these limits will require mechanical tests with greater variations in fixation heights, or studies of theoretical engineering models, which did not form part of the present study.

The mechanical property rigidity, evaluated in the present study by means of the coefficient of rigidity, indicates the capacity of the test sample to undergo deformation in response to the load applied, and that the more rigid the material, the smaller the resulting

\section{REFERENCES}

1. Albertoni WA, Faloppa F, Belotti JC. Tratamento das fraturas da extremidade distal do rádio. Rev Bras Ortop. 2002; 37(1/2):1-4

2. Fernandez DL. Rádio distal / punho. In: Rüedi TP, Murphy WM. Princípios AO do tratamento de fraturas. São Paulo: Art Méd; 2002. p. 357-77.

3. Ulson HJR. Fraturas da extremidade distal do rádio e ulna. In: Pardini Jr AG. Traumatismo da mão. Rio de Janeiro: Medsi; 1985. p. 199-246.

4. Severo AL, Mentz L, Busetto MA, Lech O, Pinto S. Fraturas da extremidade distal do rádio tratadas pela técnica de Ulson. Rev Bras Ortop. 2003; 38(8):437-45.

5. Dell'Oca AF. Fixação externa. In: Rüedi TP, Murphy WM. Princípios AO do tratamento de fraturas. São Paulo: Art Méd; 2002. p. 233-47.

6. Zar JH. Biostatistical analysis. New Jersey: Prentice Hall; 1999. deformation caused by a determined load ${ }^{(10)}$. The results obtained indicate that the most rigid system, i.e., that which deformed less in response to the applied load, was group II, with higher locking of the Kirschner wire and modification of the folding of the medial wire. However, it should be remembered that the values of group II were slightly higher than those of group I. In any case, these results contradict the mechanical concepts explained by Dell'Oca ${ }^{(5)}$ in relation to the distance between the connection with the bone and the fixation in the external fixators. The model used in the present study, which is a combination of intramedullary fixation and external fixation, as well as the simpler and more direct folding of the medial wire in group II could, in theory, explain this apparent paradox, i.e., locking of the system further from the bone, and yet, greater rigidity.

Experimental studies of intramedullary fixation with Kirschner wires in tubular bones of animals or artificial models presented controversial results, depending on variables such as diameter, number and angle of the wires, and diameter of the medullary canal of the test sample used in the tests ${ }^{(7-9)}$, which makes comparison with the results obtained in the present study inappropriate.

Comparing the conventional fixation by the Ulson method versus the fixation proposed by Severo et $a l^{(4)}$ it is noted that there was no significant difference in any of the parameters studied. To obtain better mobility in flexion and extension movements of the wrist, and facilitate the removal of the wire placed in the medial side of the radius, it can be concluded that the assembly performed in group II (locking at a height of $4.5 \mathrm{~cm}$ ) is clinically preferable.

\section{CONCLUSION}

In the conditions of the present study, the height of the locking of the Kirschner wires using the Ulson method, within the limits evaluated, did not diminish the stability of the system.

7. Oliveira Filho OM, Mazer N, Barbieri CH, Moro CA. Avaliação mecânica de diferentes métodos de osteossíntese de ossos longos pequenos. Estudo "in vitro" em metacárpicos de porcos. Rev Bras Ortop. 1995; 30(1/2):69-74.

8. Saeki Y, Hashizume H, Nagoshi M, Tanaka H, Inoue H. Mechanical strength of intramedullary pinning and transfragmental Kirschner wire fixation for Colles' fractures. J Hand Surg Br. 2001;26(6):550-5.

9. Pehlivan O, Kiral A, Mahirogullari M, Koksal O, Kaplan H. Four-point bending strength of transverse osteotomies stabilized with various Kirschner wire and tension band configurations. J Hand Surg Br. 2005;30(4):428-31.

10. Cozaciuc I, Silva LR, Togni MA. Telecurso 2000 profissionalizante, mecânica, ensaio de materiais. São Paulo: Globo; 2000. 